\title{
The Arctic Environment and the BBNJ Negotiations. Special Rules for Special Circumstances?
}

\section{Introduction}

At the moment of first writing this article, the third meeting of the Preparatory Committee (PREPCOM) on the elements of a draft text of an international legally binding instrument (ILBI) under the UN Convention on the Law of the Sea (UNCLOS) ${ }^{1}$ on the conservation and sustainable use of marine biodiversity of areas beyond national jurisdiction (BBNJ) had recently taken place at the UN Headquarters in New York City, USA. The delegations had discussed all the points of the agenda as set in the recommendations to the UN General Assembly (UNGA) by the Ad Hoc Working Group tasked with exploring this theme. ${ }^{2}$ More specifically, the mandate of the PREPCOM process, launched in 2015 by UNGA resolution A/69/292, ${ }^{3}$ was to address, "together and as a whole", ${ }^{4}$ the following items: marine genetic resources, including questions on the sharing of benefits; measures such as area-based management tools, including marine protected areas; environmental impact assessments; capacity-building and the transfer of marine technology. ${ }^{5}$ The geographic scope of the agreement, which will be an implementing agreement to UNCLOS, ${ }^{6}$ will cover all marine areas beyond national jurisdiction, hence the high seas and the Area. This means that the new BBNJ agreement will also cover the high seas portion of the Central Arctic Ocean, which is the main focus of this article. Subsequently, the fourth (and last) meeting of the PREPCOM also took place, and the PREPCOM successfully concluded its mandate, and submitted

\footnotetext{
${ }^{1}$ United Nations Convention on the Law of the Sea, 1833 UNTS 3

${ }^{2}$ Ad Hoc Open-ended Informal Working Group to study issues relating to the conservation and sustainable use of marine biological diversity beyond areas of national jurisdiction, which delivered its recommendation in UN Doc. A/69/780, Annex, Section I

${ }^{3}$ UNGA Res. A/69/292 "Development of an international legally binding instrument under the United Nations Convention on the Law of the Sea on the conservation and sustainable use of marine biological diversity of areas beyond national jurisdiction”, 19 June 2015

${ }^{4}$ UN Doc. A/66/119, 30 June 2011, Annex "Recommendations of the Ad Hoc Open-ended Informal Working Group to study issues relating to the conservation and sustainable use of marine biological diversity beyond areas of national jurisdiction and Co-Chairs' summary of discussions”, para I 1(b)

${ }^{5}$ Ibid.

${ }^{6}$ On the role of implementing agreements in the making of the law of the sea see J. Harrison, Making the Law of the Sea, Cambridge: Cambridge University Press, 2013, esp. chapter 4
} 
its report to the UNGA for formal consideration. While this article reflects the author's participation and observations during PREPCOM III, its analysis remains arguably relevant even after PREPCOM IV, given that the issues raised and discussed here have not progressed any further with PREPCOM IV. Moreover, the discussion presented here reflects more generally the overall PREPCOM process as it has unfolded in the last two years. The current state of play is that it is now up to UNGA to decide, during Autumn 2017, whether to accept the recommendation of the report of the PREPCOM, and thus "to take a decision, as soon as possible, on the convening of an intergovernmental conference". 7

The central focus of this article is the Arctic. While the Arctic has not been the focus of any formal discussion during the PREPCOM process, it appears that it has received at least some attention in the corridors, and alongside PREPCOM III a side event has specifically discussed the potential implications of a new BBNJ agreement for Arctic Governance. ${ }^{8}$ In this respect, the question this articles wishes to raise, albeit in a preliminary and exploratory manner, is whether or not the Arctic, due to its special ecological circumstances, should be regulated in some special ways within the context of the new BBNJ agreement. Of course, there are already a number of regional initiatives related to the governance of the Arctic, under the aegis of the Arctic Council or of the Arctic coastal States, dealing with fisheries, marine environmental protection, shipping etc. ${ }^{9}$ However, there is as of yet no clear idea of how the new BBNJ agreement will relate to existing regional bodies and institutions; ${ }^{10}$ no formal institution (particularly as regards fisheries) is likely to be set up in the near future with particular competence for the Central Arctic Ocean; and it seems likely,

\footnotetext{
7 "Report of the Preparatory Committee established by General Assembly resolution 69/292: Development of an international legally binding instrument under the United Nations Convention on the Law of the Sea on the conservation and sustainable use of marine biological diversity of areas beyond national jurisdiction”, Section III, para 38(2), www.un.org/depts/los/biodiversity/prepcom_files/Procedural_report_of_BBNJ_PrepCom.pdf. It must be underlined that the elements contained in the report does not reflect consensus on many key elements, see Report, Section III, para 38(1)

${ }^{8}$ A side event where the ideas presented in this article were first aired by the present writer was indeed held on April 42017 during PREPCOM III, co-organized by the K. G. Jebsen Center for the Law of the Sea and the Fridtjof Nansen Institute, under the title "Possible implications of a BBNJ (biodiversity beyond national jurisdiction) Agreement for Arctic marine governance”. For further details on this side event see https://en.uit.no/forskning/forskningsgrupper/nyheter/artikkel?p_document_id=355759\&sub_id=515749

${ }^{9}$ See for example the Oslo "Declaration concerning the Prevention of Unregulated High Seas Fishing in the Central Arctic Ocean”, the so-called Broader Process on international regulation of high seas fishing in the central Arctic Ocean, or the Arctic Marine Shipping Assessment, or the Arctic Council's Task Force on Arctic Marine Cooperation

${ }^{10}$ See, e.g. Section A of the Report's recommendations, part I, and part II, number 4 "Relationship to the Convention and Other Instruments....”, PREPCOM Report, op. cit.. It is important to recall how none of the elements contained in the report reflect consensus
} 
albeit still uncertain at this point, that the new BBNJ agreement will rely on a global management body such as a conference of the party for adopting general rules, coordinate implementation and, if and where relevant, the activities of regional bodies and institutions in relation to its mandate. ${ }^{11}$

The article will proceed as follows. Section 2 will outline the special ecological circumstances of the Arctic, its uniqueness, its special vulnerabilities and its key role in global processes such as the climate. Section 3 will show how Ocean Governance already provides for special rules linked to particular ecological circumstances, especially in relation to polar areas. In order to illustrate this, section 3 will discuss UNCLOS and the Polar Code. Section 4 will offer some reflections on how the special arctic circumstances can be addressed within a new BBNJ agreement. Finally some tentative conclusions will be presented.

Before proceeding however, it will be useful to clarify the notion of biodiversity. Based on what could be seen so far during the PREPCOM process, there seems to be a convergence between participant States towards taking onboard the notion of biodiversity contained in the Convention on Biological Diversity (CBD). Article 2 of the CBD defines biodiversity as "the variability among living organisms from all sources including, inter alia, terrestrial, marine and other aquatic ecosystems and the ecological complexes of which they are part; this includes diversity within species, between species and of ecosystems". ${ }^{12}$ The concept of biodiversity then does not refer only to biota, but also to the physical environment - the ecosystems - in which biological resources live. In other words, the concept of biodiversity is very broad, and includes both biotic and abiotic components. The new BBNJ agreement however will be an implementing agreement under UNCLOS, where there is no mention of the concept of biodiversity. States have rather, under PART XII, a duty to "protect and preserve the marine environment", 13 "including rare and fragile ecosystems”. ${ }^{14}$ Additionally, States have duties related to the conservation (and management) of living resources, particularly in the high seas, under Part VII. In this respect, it is thus useful to note how the International Tribunal of the Law of the Sea had made clear how the conservation of marine living resources is integral part of the protection and preservation of the marine

\footnotetext{
${ }^{11}$ The Report of the PREPCOM speaks of a "decision-making body/forum”, reflecting the existing uncertainties and the lack of consensus in relation to institutional arrangements, see PREPCOM Report op. cit., Section A, part IV, number 1 , p. 18

${ }^{12}$ Convention on Biological Diversity, 1760 UNTS 79, Article 2

${ }^{13}$ UNCLOS, article 192, and in general Part XII

${ }^{14}$ UNCLOS, article 194(5)
} 
environment. ${ }^{15}$ What can be concluded is that in some ways the concept of biodiversity and that of the marine environment overlap, whereas UNCLOS' concept of conservation and management of marine living resources is closer to the CBD concept of sustainable use.

\section{The Special Ecological Circumstances of the Arctic}

It is perhaps well known that the Arctic environment is unique for its ecological characteristics. ${ }^{16}$ Its ecosystems are fragile and its ecological balance is also uniquely vulnerable. Arctic biodiversity is uniquely adapted to extreme and seasonally variable conditions. Indeed, the Arctic environment is an area of "heightened ecological significance", according to the latest Arctic Marine Shipping Assessment produced under the Aegis of the Arctic Council. ${ }^{17}$ Yet its ecosystems are threatened by a series of global, regional and local processes which are changing the ecological as well as the socioeconomic conditions of the Arctic. The fragile and vulnerable arctic ecosystems are in fact undergoing dramatic changes. Most of the harmful effects on Arctic ecosystems are the result of activities and processes that are either global in nature, such as climate change, or occur elsewhere. With regards to climate change in particular, the arctic exhibits accelerated warming, leading to dramatic decrease in sea ice cover and warmer and wetter conditions, threatening arctic biodiversity. ${ }^{18}$ The most prominent and unique feature of the Central Arctic Ocean is the drift pack ice. ${ }^{19}$ This unique habitat hosts many ice-dependent species which make up a "very special biota”, ${ }^{20}$ including seven species of marine mammals: ${ }^{21}$ polar bears, as well as several species of seals $^{22}$ and of whales. ${ }^{23}$ The effects of climate change on the extent of summer ice and on ocean temperatures as well as circulation patterns is changing a number of the ecological dynamics of the region, thus posing several threats to ice-dependent species, Moreover, climate change is

\footnotetext{
${ }^{15}$ ITLOS, Southern Bluefin Tuna cases (New Zealand v. Japan; Australia v. Japan), Order, 27 August 1999, para 70 ${ }^{16}$ See foe example the latest SWIPA Report, AMAP, Snow, Water, Ice and Permafrost in the Arctic. Summary for Policymakers, 2017

${ }^{17}$ AMAP/CAFF/SDWG, Identification of Arctic marine areas of heightened ecological and cultural significance: Arctic Marine Shipping Assessment (AMSA) IIc, part of the Arctic Council’s Arctic Marine Shipping Assessment

${ }^{18}$ AMAP, 2017, op. cit., ${ }^{19}$ PAME, Central Arctic Ocean LME, 13/18: LME Factsheet Series, p. 2 
already leading to changes in the distribution and abundance of species across the Arctic environment. ${ }^{24}$

As regards the transfer of pollutants and other harmful effects from elsewhere, one example is the transport of plastic debris towards the Arctic from other ocean areas, through ocean circulation patterns. ${ }^{25}$ In fact, while microplastics have been found embedded in arctic sea ice core, ${ }^{26}$ recent research has shown the formation of floating plastic debris accumulation spots in the Greenland and Barents seas. ${ }^{27}$ As the recent study observed, "fragmentation and typology of the plastic suggested an abundant presence of aged debris that originated from distant sources”. ${ }^{28}$ Moreover, the same study suggests that the "seafloor beneath this Arctic sector" may be "an important sink of plastic debris". ${ }^{29}$ As the same study emphasizes, “[t]he uniqueness of the Arctic ecosystem makes the potential ecological implications of exposure to plastic debris of special concern”. ${ }^{30}$ Additionally, the decrease in summer ice is leading to the opening of previously inaccessible areas, fueling new commercial interests in the Arctic Ocean in relation to fisheries, new shipping routes, and mineral extraction. ${ }^{31}$ All of these changes create increasing pressures and threats to Arctic marine biodiversity and to the Arctic environment.

\section{Existing Special Rules for the Arctic}

International law has always been sensitive to special circumstances, both subjective ${ }^{32}$ and objective. As much as law intends to subsume reality into neat general and abstract rules, particular circumstances inevitably demand specialized rules adapted to the uneven fabric of the real world.

\footnotetext{
${ }^{24}$ CAFF, Arctic Biodiversity Assessment, Status and Trends in Arctic Biodiversity, Conservation of Arctic Flora and Fauna, Akureyri, 2013

${ }^{25}$ A. Cozar et alia, 'The Arctic Ocean as a dead end for floating plastics in the North Atlantic branch of the Thermohaline Circulation’, Science Advances, 3:4, 2017

${ }^{26}$ R. Obbard et alia, “Global Warming Releases Microplastic Legacy Frozen in Arctic Sea Ice”, Earth's Future, 2:6, 2014. Sea ice, as it forms, scavenges and concentrates particulates from the water column. If the water column contains microplastics, such debris are captured in the ice during the formation process.

${ }^{27}$ Cozar et alia, 2017, op. cit.

${ }^{28}$ Ibid., abstract

${ }^{29}$ Ibid. abstract. See also M. Tekman, T. Krumpen and M. Bergmann, "Marine litter on deep Arctic seafloor continues to increase and spreads to the North at the HAUSGARTEN observatory", Deep Sea Research Part I: Oceanographic Research Papers, 120, 2017

${ }^{30}$ Ibid. p. 6

31 The question of new and exploratory fisheries is at the moment being addressed via arctic regional initiatives mentioned in the introduction. The safety and environmental questions raised by the opening of new shipping routes is partially addressed through the Polar Code.

32 The relevance of subjective circumstances translates for examples in special treatment under the WTO regime, or the principle of Common but Differentiated Responsibility within the climate context. See in general L. Rajamani, Differential Treatment in International Law, Oxford: OUP, 2006
} 
International legal rules related to environmental protection, regardless of the regime or institutional provenance, are no exception. This section will offer some examples in order to illustrate how there already exist, within the context of ocean governance, special rules crafted in order to account for special ecological circumstances. These may offer a conceptual and legal platform to support my argument that the Arctic environment requires special rules of some sort, and may offer a starting point for devising such special rules. The next two subsections will discuss, respectively, some provisions of the United Nations Convention on the Law of the Sea (UNCLOS), and then the International Code for Ships Operating in Polar Waters (Polar Code) adopted by the International Maritime Organization (IMO) and recently entered into force.

\subsection{UNCLOS}

The relevant part of UNCLOS is Part XII, devoted to the protection and preservation of the marine environment. By way of a general remark, the environment is a prominent element of UNCLOS, ${ }^{33}$ and was one of the main objectives of the new law of the sea during the negotiations. ${ }^{34}$ Besides all the general rules however, Part XII recognizes that some special or exceptional circumstances should be the basis for special legal treatment or rules, as necessary. The first, and most general of these special rules is the one contained in article 194(5), which establishes that the measures contained in Part XII "shall include those necessary to protect and preserve rare or fragile ecosystems as well as the habitat of depleted, threatened or endangered species and other forms of marine life”. This provision, according to some eminent commentators, provide indeed the basis for special treatment of rare and fragile ecosystems, ${ }^{35}$ as we shall see presently. A second example of special rules being established in light of special ecological circumstances is article 211 . Article 211 deals with pollution from vessels, and in paragraphs 3 through 6 it establishes the rules governing the competence of Coastal States in relation to the regulation of foreign vessels. Of special interest is paragraph 6 . The reference against which to read paragraph however is paragraph 1 of the same article 211, which sets out that States "through the competent international organization or general diplomatic conference, shall establish international rules and standards to prevent, reduce and control pollution of the marine environment from vessels”. However, where there exist special circumstances - in particular relating to particular "oceanographical and

\footnotetext{
${ }^{33}$ As evident already in the Preamble of UNCLOS.

${ }^{34}$ N. Nordquist , S. Nandan, and S. Rosenne, United Nations Convention on the Law of the Sea 1982 Commentary online, Leiden: Brill-Nijhoff, 2013, “Part XII - Articles 192-237”, p. 3

${ }^{35}$ Ibid., p. 68
} 
ecological conditions”36 - that render the general rules and standards mentioned in paragraph 1 "inadequate", ${ }^{37}$ Coastal States may adopt "special mandatory measures for the prevention of pollution from vessels" 38 in the relevant special areas (that is, "clearly defined area of their respective exclusive economic zones"). ${ }^{39}$ The procedure to adopt such rules requires consultations with other States through competent international organizations, as well as communication and submission of relevant technical and scientific documentation. The procedural details however are not of special interest for our purposes. What is relevant to note on the other hand is the very fact that special circumstances may render inadequate existing general rules and standards, and may indeed make necessary the adoption of special mandatory measures in light of the oceanographic or ecological particularities of a specific area.

Finally, and returning to the special treatment that, pursuant to article 194(5), may be afforded rare and fragile ecosystems, ${ }^{40}$ we shall have a look at article 234. Article 234 deals with ice-covered areas, and has been called the "arctic article". ${ }^{41}$ Article 234 is outstanding in the context of Part XII, as it allows coastal States to adopt their own laws and regulations within its exclusive economic zone so long as they are non-discriminatory. This provision functions as lex specialis vis-à-vis article 211(6), at least in relation to its geographical scope (that is, ice-covered areas). ${ }^{42}$ What this means is that coastal States may impose more stringent regulations (than international rules and standards) in order to prevent, reduce and control marine pollution from vessels, and in light of "particularly severe climatic conditions and the presence of ice covering such areas for most of the year", ${ }^{43}$ conditions that may determine "exceptional hazards to navigation, and pollution of the marine environment could cause major harm to or irreversible disturbance of the ecological balance". ${ }^{44}$ What is important to highlight here is that the special rules (and the special competence to coastal States) are linked crucially to the objective of preventing major harm or irreversible disturbance to the ecological balance.

\footnotetext{
${ }^{36}$ UNCLOS, Article 211, para 6

${ }^{37}$ Ibid.

${ }^{38}$ Ibid.

${ }^{39}$ Ibid.

${ }^{40}$ Nordquist, Nandan and Roselle indeed observe how article 234 "picks up the theme of article 195, paragraph 5, with its reference to rare and fragile ecosystems”, ibid., p. 393

${ }^{41}$ Ibid., p. 393

${ }^{42}$ Ibid., p. 393

${ }^{43}$ UNCLOS, Article 234

${ }^{44}$ Ibid.
} 
It must be noted that these special provisions relate to special competence conferred to coastal states for a public interest role they may fulfil in relation to the protection and preservation of the marine environment, and in particular of that portion of the marine environment located within their exclusive economic zones. Yet what is crucial to emphasize is not the specifics of the provisions, but the fact that special spatial and ecological circumstances are indeed recognized within the context of UNCLOS as a sufficient ground for adopting special rules, to the extent that general rules and standard may prove inadequate.

\subsection{IMO's Polar Code}

Another instrument that has adopted special rules in order to accommodate the special geophysical and ecological circumstances of polar areas is IMO's Polar Code. Its twofold objectives are safety of navigation and environmental protection in the inhospitable waters of the two poles. The special rules were warranted given the particularly harsh and difficult climatic conditions, including, importantly, the ice-covered waters. The provisions related to safety of navigation, and the related amendments to the International Convention for the Safety of Life at Sea (SOLAS), were adopted by IMO’s Maritime Safety Committee (MSC), at its $94^{\text {th }}$ session, in November $2014 .{ }^{45}$ The rules especially devised to ensure the protection of the fragile and vulnerable environment of the polar areas, and the related amendments to the International Convention for the Prevention of Pollution from Ships (MARPOL), were adopted by IMO’s Marine Environmental Protection Committee (MEPC) at its $68^{\text {th }}$ session, in May $2015 .{ }^{46}$ With respect to the environment, the Polar code contains both mandatory and recommendatory provisions on pollution prevention. In Arctic waters, according to those provisions, ships cannot discharge oil and oily mixture; ${ }^{47}$ cannot discharge noxious liquid substances; ${ }^{48}$ cannot discharge sewage, with degrees of prohibitions related to

onboard treatment capabilities; ${ }^{49}$ cannot discharge garbage, again with degrees of prohibitions related to types of garbage, plastic being always prohibited, while food wastes are fully prohibited

\footnotetext{
${ }^{45}$ Resolution MSC.386(94) for the SOLAS amendments, and Resolution MSC.385(94) for the Polar Code provisions, both adopted 14 November 2014

${ }^{46}$ Resolution MEPC265(68) for the MARPOL amendments and Resolution MEPC.264(68) for the environmental provisions of the Polar Code, both adopted 15 May 2015

${ }^{47}$ Polar Code, Part II-a, “Pollution Prevention Measures”, MEPC 68/21/Add.1, Annex 10 Chapter I

${ }^{48}$ Ibid., Chapter II

${ }^{49}$ Ibid., Chapter III
} 
only onto ice. ${ }^{50}$ There exist also structural requirements, that is requirements directly related to ship construction.

There exist other special rules devised to account for the especially vulnerable conditions of the Arctic and Antarctic environment, such as those related to the regulation of invasive and alien species in Antarctica, ${ }^{51}$ or the IMO guidelines for ballast exchange, also in Antarctica. ${ }^{52}$ However, for the purposes of this article, the examples offered by UNCLOS and by the Polar Code are arguably sufficient.

\section{Imagining Special Arctic Rules in a BBNJ Agreement}

As we have seen, UNCLOS contains some special rules aimed at taking into account special ecological conditions that may render general international rules and standards inadequate for the purposes of protecting and preserving the marine environment and marine biodiversity in those particularly vulnerable areas. The question this article wished to raise and discuss is whether or not special rules could or should be devised under the new BBNJ agreement for the protection of Arctic biodiversity given the special vulnerabilities of the Arctic environment, of its ecosystems and of its biodiversity. As this is a preliminary exploration, the article will only offer some reflections on a limited number of options. Current negotiations, and the specific debates on relevant themes or mechanisms, will be used as the starting point. In particular, this article will focus on special rules that would be conceivable in relation to environmental impact assessments. Albeit related, options in relation to area based management or marine protected areas will not be explored, not directly at least. The article will also explore some possibilities in relation to how to accommodate these and other conceivable special rules within a new BBNJ agreement, for example by way of a special “arctic provision”, following the model of article 234 of UNCLOS, or by way of an Arctic Annex, with a broader scope. Secondarily, the article will explore the idea of a special Arctic working group that could, subsequent to the adoption of the new BBNJ

\footnotetext{
${ }^{50}$ Ibid., Chapter IV. Some of these prohibitions are qualified in a variety of technical, spatial, temporal and legal manners, for example in relation to whether or not ships are compliant with existing rules under MARPOL (see e.g. article 4.2.1), or in relation to the category and time of construction of ships. For the detailed provisions, see Polar Code, Part II-a, op. cit., p. 38ff.

${ }^{51}$ E.g. Recommendation ATCM III-VIII (Brussels, 1964) on "Agreed Measures for the Conservation of Antarctic Fauna and Flora” or Conservation Measure 26-01 (2009) adopted under the Convention on the Conservation of Antarctic Marine Living Resources (CCAMLR), 1329 UNTS 48

${ }^{52}$ ATCM Resolution 3(2006) on 'Ballast Water Exchange’, adopting IMO’s “Guidelines for Ballast Water Exchange in the Antarctic Treaty Area”
} 
agreement, follow up on Arctic matters and ensure, in light of the special vulnerabilities of the Arctic environment, that adequate rules and standards for conservation of its biodiversity are adopted and implemented.

\subsection{Special rules for Environmental Impact Assessments?}

Environmental Impact Assessments is one of the four agenda items of which the package agreed in 2011, with resolution A/66/199, is comprised. During PREPCOM III discussion on EIAs took place in an informal group first, and then in plenary. Many delegations, during the opening interventions, generally referred to the relevant UNCLOS articles with the idea that such articles should act as a starting point. ${ }^{53}$ The discussion however brought to the fore a number of issues over which no consensus emerged, nor was reached at the end of the PREPCOM process, ${ }^{54}$ even though some convergence of views certainly exists. In particular, some questions received significant attention. ${ }^{55}$

The first of these questions having a specific relevance for this paper is the question of triggers. This discussion item refers to the particular circumstances that ought to trigger an environmental impact assessment (EIA). In other words, the question to be answered is: when should an EIA be carried out? An additional, and related, question hinged on whether an indicative (Australia, New Zealand) or exhaustive list of activities that may or must (Norway) require an EIA, should be included in the new BBNJ agreement or not, and whether this list should be dynamic (Norway, Australia) or fixed. ${ }^{56}$ Some (Japan) argued adamantly that no EIA should be required for activities already regulated under other regimes. ${ }^{57}$

\footnotetext{
${ }^{53}$ UNCLOS, articles 204-206, and especially 206. The latter is the explicit starting point in the PREPCOM Report op. cit., Section A, part III, number 5.1

${ }^{54}$ As already mentioned, the report of the PREPCOM to UNGA does not reflect consensus, PREPCOM Report, op. cit.

55 The report from PRECOM III discussion are based on a combination of the notes taken by the author, who assisted to the relevant sessions and to the debates, on the summary provided by Earth Negotiation Bulletin, "Summary of the Third Session of the Preparatory Committee on Marine Biodiversity beyond Areas of National Jurisdiction", 25: 129, 10 April 2017, <http://enb.iisd.org/vol25/enb25129e.html> (hereinafter "ENB, PREPCOM Final”), and on the statement of the delegations during the debates, as retrieved through UN Paper Smart system. The latter will be referred to by country and date and time.

${ }^{56}$ Author's notes. China and USA were against including lists, the former preferring a case by case determination, the latter considering that the negotiation of a list would be lengthy and difficult to conclude, and would rather simply refer to art. 206 of UNCLOS, author's notes. New Zealand also supported a case-by-case determination, yet supported also the inclusion of an indicative list, ENB "PREPCOM Final”, p. 8

${ }^{57}$ Author's notes. No view is expressed in this respect in the PREPCOM Report op cit., where Section A, Part III, number 5.2 simply states that "The text [of an agreement] would set out the relationship to environmental impact
} 
A second question which has a special relevance for this paper, and which is related to the previous one, is the question of thresholds. A threshold refers to the level of harm that can or should be reasonably expected to be caused by an activity, and whether that level of harm should trigger an EIA. According to article 206 of UNCLOS, which as mentioned has been referred to widely by delegations as the starting point of discussions on EIAs, when States have "reasonable grounds for believing that planned activities under their jurisdiction or control may cause substantial pollution of or significant and harmful changes to the marine environment”, they shall assess such risks. Ecuador, speaking on behalf of G77/China has indeed referred explicitly to the thresholds and legal basis for EIA established in UNCLOS. ${ }^{58}$

Both in terms of triggers and of thresholds there is evident scope for some special provisions that, besides and beyond the general contextual nature of risk assessments, take structurally into account the special fragility and vulnerability of the Arctic environment, in order to achieve the objective of the conservation of arctic biodiversity, also taking into account the obligations States have under UNCLOS to protect and preserve the marine environment, and UNCLOS' own specialized arctic provision discussed above.

A third question relates to transboundary impacts, that is, impacts that are caused by activities that occur in a different maritime zone. On this point as well there is a relevant UNCLOS provision, namely article 194, which establishes that "States shall [...] ensure that [...] pollution arising from [...] activities under their jurisdiction or control does not spread beyond the areas where they exercise sovereign rights". Yet on this point there is significant divergence of views and perspectives. Indeed, the view that EIAs should be carried out under the rules of the new BBNJ agreement also for activities that, while taking place in areas within national jurisdiction, may have impacts in areas beyond national jurisdiction, is contrasted by views that suggest the opposite. Norway, for example, suggested to include impacts of activities taking place in ABNJ that may have impacts in areas within national jurisdiction. ${ }^{59}$ Others wanted to consider mechanisms for consulting with potentially affected States in case of transboundary EIAs that may affect their EEZ

assessment processes under relevant legal instruments and frameworks and relevant global, regional and sectoral bodies".

${ }^{58}$ Ecuador, on behalf of G77/China, March, 29 2017, 5.00pm, $<$ http://statements.unmeetings.org/media2/14683772/ecuador_statement_bbnj_eias.pdf>

${ }^{59}$ Author's notes 
(e.g. Fiji and China), ${ }^{60}$ while some suggested there should be a requirement of consent on the part of States whose marine areas may be affected by activities to be carried out in ABNJ (VietNam). ${ }^{61}$

In many ways these views express two sides of what in reality should be considered as a single question: the integrated environmental governance of oceans. EIAs then is inseparable from an ecosystem approach to ocean governance, which in turn suggests the reasonable rules that should be adopted, outside of any parochial calculation or national perspective. Indeed, it makes little sense to continue to protect and preserve the marine environment (in particular through the perspective of the conservation of biodiversity) in a fragmented and sectoral basis. The new BBNJ agreement is in this respect a golden opportunity (and despite the reiterated and convergent calls to not undermine the mandates of existing bodies and institutions) ${ }^{62}$ to facilitate and coordinate integrated conservation measures, and to articulate a legal framework that allows an ecosystem perspective and an ecosystem approach to the matter of conservation of biodiversity. ${ }^{63}$ Bringing this remarks closer to the arctic, it will be useful to mention that the Central Arctic Ocean large marine ecosystem, identified by the Arctic Council as the key platform for an effective implementation of an ecosystem approach to arctic environmental protection and biodiversity conservation, is not a one to one match to the high seas portion of the Central Arctic Ocean. ${ }^{64}$ It is, indeed, larger, and includes portions of the EEZ of four Arctic Coastal States (Canada, Norway, Denmark/Greenland, Russia). ${ }^{65}$ This entails that an effective program of conservation of arctic biodiversity must be able to include in its purview all relevant activities in all ecologically relevant zones, regardless of jurisdictional fragmentation. The institutional tool to achieve such goal remains of course subject to negotiation and, probably, contestations. Yet it appears reasonable to

\footnotetext{
${ }^{60}$ China however suggests that there is no need to elaborate rules for EIA of activities under national jurisdiction having an impact in ABNJ, as UNCLOS already regulates such cases in article 194, China, Statement, March, 29 2017, 5.21pm, <http://statements.unmeetings.org/media2/14683576/china_eia_en.pdf>

${ }^{61}$ Author's notes. The relevant text in the PREPCOM Report, while simply setting out the scope of the article, seem to suggest that relevant activities, with respect to triggering EIAs, should be those occurring in ABNJ

${ }^{62}$ A goal already contained in the mandate to the PREPCOM, UNGA resolution A/69/292, para $\mathrm{k}(3)$

${ }^{63}$ For a critical analysis of the ecosystem approach in international environmental law see V. De Lucia, 'Competing Narratives and Complex Genealogies: The Ecosystem Approach in International Environmental Law', Journal of Environmental Law, 27:1, 2015, 91. For a commentary on the role of the ecosystem approach within the context of the discussion under the PREPCOM see V. De Lucia, 'The Ecosystem Approach for Areas Beyond National Jurisdiction: Reflections on the Chair's non-paper ahead of "PREPCOM III”', JCLOS blog, 20 March 2017, $<$ http://site.uit.no/jclos/2017/03/20/the-ecosystem-approach-for-areas-beyond-national-jurisdiction-reflections-onthe-chairs-non-paper-ahead-of-prepcom-iii/>

${ }^{64}$ PAME, Central Arctic Ocean LME, op. cit.

${ }^{65}$ PAME, Central Arctic Ocean LME, op. cit.
} 
explicitly and especially consider these elements in relation to the fragile and vulnerable arctic environment, and accommodate them, within the new BBNJ agreement, by way of some special substantive and/or procedural provisions.

From a substantive perspective, special arctic triggers and thresholds could be conceived so as to explicitly account for the fragility and vulnerability of the arctic environment in ABNJ. For example, and without prejudice for the general rules to be adopted in a new BBNJ agreement, an arctic provision could make EIA mandatory for all activities taking pace in the Arctic ABNJ, or having potential impacts on biodiversity in the Arctic ABNJ, regardless of in which maritime zone they occur (though some geographical delimitation would be certainly necessary). This can be justified on the basis that recovery times from perturbations in fragile and vulnerable ecosystems are much slower than in other areas, and their integrity is much more susceptible to changes that are either irreversible, or reversible only over long period of times. ${ }^{66}$

From a procedural point of view, special rules could be devised in order to ensure that activities within and beyond national jurisdiction, as well as those occurring in ABNJ under the sectoral or geographical jurisdiction of international organizations, are coordinated with regards to EIAs. Here the question intersects with the related question of the role of existing regional bodies. It is much too complex to address here. The only remark that can be offered is that it would be unreasonable to duplicate mechanisms and the real challenge is to ensure cooperation and coordination, within the scope of the respective mandates. Perhaps the EBSA process ${ }^{67}$ could offer a model to be replicated in other respects in a new BBNJ agreement, where particular competence remains disaggregated, but there is a central coordination mechanism to ensure coherence and produce global guidelines and scientific and technical advice where necessary. The EBSA process is of course a relevant reference point also in relation to another of the agenda items under discussion, namely area based management tools, including marine protected areas (MPAs). However, the question of area based management in the arctic is much too complex to address here, from both

\footnotetext{
66 The reference here is to the concept of ecological integrity contained in CCAMLR, whose primary objective is that of preventing "changes or [minimising] the risk of changes in the marine ecosystem which are not potentially reversible over two or three decades”, CCAMMLR, article II (3)(b)

${ }^{67}$ EBSA stands for Ecologically and Biologically Significant Marine Areas. The CBD has adopted scientific criteria for the identification of EBSAs (COP Decision IX/20, "Marine and Coastal Areas”, UNEP/CBD/COP/DEC/IX/20) and a number of decisions relating to capacity building and information-sharing (e.g. COP Decision X/29, "Marine and Coastal Biodiversity, UNEP/CBD/COP/DEC/X/29”)
} 
a substantive and procedural perspective (and would certainly require also a discussion of another relevant sectoral tool that is available under the IMO, particularly sensitive sea areas). ${ }^{68}$ Many delegations were positive also in relation to the inclusion of rules on Strategic Environmental Assessment (SEA). SEAs are crucial tools for a spatially and temporally broader assessments of a large range of individual projects or activities and are more closely linked to the ecosystem approach and to the identification and designation of marine protected areas. ${ }^{69}$ This point will be further discussed in the next sections, especially when discussing the potential scope for an Arctic working group to be set up under the new BBNJ agreement, and its imagined competence.

\subsection{An Arctic Provision?}

Another possibility is to devise a special "arctic" provision, modeled, mutatis mutandis, on article 234 of UNCLOS. One such provision could contain the legal basis for adopting special rules in light of the specific ecological circumstances of the Arctic environment, and perhaps also the procedural steps required, similarly to article 211 of UNCLOS. It could for example open for the adoption of special rules to be agreed by the relevant decision-making body (the COP), pursuant to scientific recommendations prepared by a subsidiary body likely to be set up under a new BBNJ agreement.

\subsection{An Arctic Annex?}

Another option could be an Arctic Annex. An Arctic Annex could be a singularly effective way to include special rules or to establish the mechanisms or procedures to adopt special rules in the future, independently from the main agreement. This would allow more flexibility and ensure a dynamic and adaptive way to face the specific challenges of the Arctic environment. An Annex would be a container for all potentially relevant substantive and procedural rules specific to the Arctic. Another advantage of an Annex, besides perhaps the negotiating advantages of disentangling the negotiation on the main text from that of an Annex, is that it could be modified via a leaner procedure, for example on the model of the Fish Stock Agreement. ${ }^{70}$ However, it

\footnotetext{
${ }^{68}$ For an overview of particularly sensitive sea areas, and for the relevant guidelines, see IMO, Revised Guidelines for the Identification and Designation of Particularly Sensitive Sea Areas, IMO Resolution A.982(24), 2006

69 These last considerations on the interaction between EIAs and MPAs would merit further attention, but that will need to be done in another occasion

${ }^{70}$ Where Annexes can be modified without triggering the amendment procedure, if State Parties reach consensus at a State Parties meeting, article 48(2), Agreement for the Implementation of the Provisions of the United Nations Convention on the Law of the Sea of 10 December 1982 Relating to the Conservation and Management of Straddling Fish Stocks and Highly Migratory Fish Stocks, 1995, 34 ILM 1542 (FSA)
} 
would be perhaps best to use Annexes for specific thematic areas or tools, such as the ecosystem approach, ${ }^{71}$ rather than for the creation of special rules for a particular geographic area.

\subsection{An Arctic Working Group under the New BBNJ Agreement?}

Another possible way to address the special ecological circumstances of the Arctic, yet without establishing from the beginning special rules, is the creation of a specialized working group on arctic biodiversity. Its mandate could be wide, but it would at a minimum include exploring potential needs for special rules, coordinating with other arctic initiatives, institutions and actors, as well as with the Arctic Coastal States, both in relation to policy and to scientific knowledge.

In this respect however it will be important to understand the role that a future Conference of the Parties to the new BBNJ agreement would have, and especially the type of decision-making competence it would have, in order to understand whether the working group could in fact prepare recommendations that the COP could adopt as decisions under the new BBNJ agreement, on the model of, e.g., the CBD, or whether the competence of the COP would be more limited. Additionally, it will be important to understand the potential role for a Subsidiary Body for Scientific and Technical Advice, also discussed as a potential relevant body under the new BBNJ agreement, which may take an important role with regards to liaising with other bodies producing relevant scientific knowledge.

\section{Conclusions}

This article has endeavored to imagine some ways in which the special ecological circumstances could be taken into account under a new BBNJ agreement. The legal starting point of my exploration has been the fact that ocean governance today already provides for the possibility to adopt special rules on the basis of special ecological circumstances, and in order to overcome the inadequacy of general rules and standards with respect to the protection and preservation of the marine environment and, given the significant overlap between the two concepts, the conservation of marine biodiversity.

In any case, the goal of this exploration was not so much that of identifying, with any degree of precision, rules - substantive and procedural - that could ensure the effective conservation of

\footnotetext{
${ }^{71}$ See WWF submission for PREPCOM III, WWF, Proposed framework and key elements of a third UNCLOS Implementing Agreement, WWF submission to the BBNJ PrepCom Chair and to DOALOS for PrepCom 3, 5 December 2016, <www.un.org/depts/los/biodiversity/prepcom_files/rolling_comp/World_Wildlife_Fund.pdf>
} 
Arctic biodiversity in the face of the special ecological circumstances of the Arctic environment. It was rather that of opening a discussion on these themes, to stimulate some debate, and the begin to articulate a series of possible ways that could be further explored in the near future, once the formal diplomatic conference towards the adoption of a new BBNJ agreement will commence, at it seems likely it will. Especially as there seems to be a good likelihood that an intergovernmental conference be launched by the UNGA, and keeping in mind how the PREPCOM Report offers only limited guidance, and no consensus view, there seems to be ample scope for, and much to gain from, discussions on whether special rules are necessary to safeguard the especially vulnerable Arctic environment. 